\title{
When night never falls: female sexual signalling in a nocturnal insect along a latitudinal gradient
}

\author{
Anna-Maria Borshagovski ${ }^{1,2}$ - Paulus Saari ${ }^{3} \cdot$ Topi K. Lehtonen $^{1,2} \cdot$ Arja Kaitala $^{1,2}$
}

Received: 21 April 2020 / Revised: 19 October 2020 / Accepted: 30 October 2020 / Published online: 27 November 2020

(C) The Author(s) 2020

\begin{abstract}
The environment can play an important role in animal communication by affecting signal transmission and detection. Variation in the signalling environment is expected to be especially pronounced in widely distributed species, potentially affecting how their signals are detected. Such environmental variability is presumably relevant for sedentary females of a nocturnal capital breeder, the European common glow-worm (Lampyris noctiluca), which produce green light during the night to attract flying males to mate. Being widely distributed in Europe, glow-worm populations are exposed to both rapidly descending, darker summer nights in the south, and slowly dimming, brighter summer nights further north, with the latter potentially posing challenges to the visibility of the female glow. To test how female signalling is affected by latitude, we sampled glowing females during summer nights along a latitudinal gradient in Finland, Northern Europe, and used a novel apparatus to measure the intensity and peak wavelength (hue/colour) of their glow. Surprisingly, females at higher latitudes, similar to those at lower latitudes, were commonly glowing during the brightest (and hence the shortest) nights of the year. Females also glowed brighter in more northern areas, partly due to their larger body size, whereas the colour of their glow was not associated with latitude. Since females glow even during midsummer, independent of latitude, the increase in glow intensity at higher latitudes presumably serves to maintain signal visibility in brighter signalling conditions. Overall, these findings highlight the influence of environmental conditions on the evolution of sexual signals, especially in the context of species distribution range.
\end{abstract}

\section{Significance statement}

When environmental conditions impact signal transmission and perception, local conditions can have a crucial role in shaping animal communication and signal evolution. To analyse how dark-dependant common glow-worm females cope with variable nocturnal light environments, we used a novel apparatus, presumably not applied to living animals before, to measure female glow intensity at various latitudes along a latitudinal gradient. Interestingly, females did not avoid signalling during the brightest summer nights, but instead, their glow intensity and body size both increased with latitude. These findings suggest that females can ensure visibility to mate-searching males over a range of local conditions. Our study therefore shows how females can adapt to environmental constraints on signal visibility, and how the expression of sexual signals is shaped not only by social interactions but also by the signalling environment.

Keywords Visual signals $\cdot$ Light conditions $\cdot$ Lampyris noctiluca $\cdot$ Glow-worm $\cdot$ Bioluminescence

Communicated by D. Kemp

Anna-Maria Borshagovski

anna-maria.borshagovski@oulu.fi

1 Ecology and Genetics Research Unit, University of Oulu, PO Box 3000, FI-90014 Oulu, Finland

2 Tvärminne Zoological Station, University of Helsinki, J.A. Palménin tie 260, FI-10900 Hanko, Finland

3 Nano and Molecular Systems Research Unit, Biophysics group, University of Oulu, PO Box 3000, FI-90014 Oulu, Finland

\section{Introduction}

Signals lie at the core of animal communication. They include morphological, physiological, and behavioural traits that are used to pass information between individuals (Otte 1974). In the context of sexual selection, signals may confer information about the signaller's quality and sexual availability to members of the opposite sex (Andersson 1994). Sexual selection favours signals that can most effectively deliver the message in the signalling environment and arouse the wanted response from potential mating partners, increasing the fitness 
of the signaller (Endler 1992, 2000). Larger, brighter, and louder signals are the easiest to detect and often the most efficient at both active mate choice and passive mate attraction (Bateson 1983; Andersson 1994). The receiver's sensory and cognitive abilities, however, affect its mate choice processes, limiting the potential functions of the transmitted signal and, therefore, signal evolution (Ryan 1990). As an example of such limitations, human eyes cannot detect UV light, and hence, we fail to respond to any signals solely from the UV range. Moreover, signal processing may impact aspects of the receiver's sensory system, including its photoreceptors' spectral sensitivity (Endler 1992; Rowe 1999; Cronin et al. 2014). For instance, a signal consisting of a particular range of wavelengths may select for the receiver's spectral sensitivity to match the signal, allowing more efficient signal processing (a higher signal to noise ratio), as seen in some species of fish (Lythgoe and Partridge 1989; Bowmaker 2008), terrestrial vertebrates (Fleishman 1986; Ryan 1990), and insects (Alexander 1962; Seliger et al. 1982b; Bernard and Remington 1991; Cronin et al. 2000).

Besides the interactions between signallers and receivers, the signalling environment may also shape signal evolution by affecting signal detection (Endler 1993a, 2000; Endler and Basolo 1998; Brumm 2004; Cole 2013). Signals travel from a sender to a receiver through a medium, such as air or water. The properties of the medium, together with the local conditions, are likely to affect whether the signal reaches the receiver, and if it does, how it is perceived (Endler 1990, 1991; Gamble et al. 2003; Smit et al. 2019). Therefore, a certain signal property (for example, an acoustic frequency) may be conspicuous in one environment, but appears different to, or disappears altogether from, a receiver in another. In other words, signal conspicuousness and efficiency are relative measures (Endler 1992, 1993a; Jennions and Petrie 1997). When the signaller cannot efficiently control its signalling environment, it may increase its signal conspicuousness by adjusting the contrast between the signal and the signalling environment. This is possible by adjusting the signalling behaviour, for example, by choosing a signalling time or environment that maximises the signal to noise ratio, or by modifying the signal itself (Endler 2000). For instance, the effects of background noise can be minimised by signals that greatly differ from the signalling environment, as seen in Anolis lizards, which bob their head at a frequency different from the movements of the surrounding vegetation (Endler 1992). In the context of colours used in communication, highly represented wavelengths of ambient light can also be relevant to improve signal to noise ratio. For instance, a colour patch of an animal is perceived brighter when it matches the ambient light spectrum, increasing the overall contrast between the signaller and the environment. Similarly, a mismatch between the reflectance and ambient light spectra can result in a duller signal (Endler 1990, 1991). From a receiver's point of view, its spectral sensitivity may, in a relatively stable environment, evolve to match light conditions of the environment (Endler 1992; Leal and Fleishman 2002; McComb et al. 2010), which demonstrates the intimate links between the signaller, the receiver, and the signalling environment (Endler 2000; Cole 2013).

Light is a key environmental factor affecting living organisms. Depending on latitude, local populations are affected differently by the temporal distribution of light, for instance, in terms of the timing of reproduction, migratory behaviour, and mate attraction signals (Leal and Fleishman 2004; Hansson et al. 2007; Bradshaw and Holzapfel 2010; Shieh et al. 2017). During summers at high latitudes, nights are short and relatively bright, dusk and dawn are long, and ambient light consists of longer wavelengths than closer to the equator (Endler 1993b; Mills 2008). An individual close to London $\left(\mathrm{N} 51.5^{\circ}\right)$ at the beginning of July experiences about $2 \mathrm{~h}$ less of night-time than one close to Madrid (N40.4 ${ }^{\circ}$ ) (as measured from the apparent sunset to the apparent sunrise; https://www. esrl.noaa.gov/gmd/grad/solcalc/). An individual to the north of N66. $5^{\circ}$ would, in turn, not experience any dark period at the end of June. Such variation in environmental light conditions may have a significant impact on visual signalling in nocturnal and twilight-active species (Biggley et al. 1967; Lall et al. 1980; Hall et al. 2016).

Most visual signals function by reflecting ambient light and thus are transmitted during daytime. Because visual signals have limited use for nocturnal animals, olfactory and acoustic signals are often their dominating signal types. However, the relationship between signals and the signalling environment is very relevant for animals that signal with bioluminescent light, such as fireflies and glow-worms (Coleoptera: Lampyridae) (Endler 1992). Most Lampyrid beetles are nocturnal or duskactive and exhibit large among-species variation in glowing properties (Lewis and Cratsley 2008). Notably, the peak wavelength $\left(\lambda_{\max }\right)$ of the glow ranges from $546 \mathrm{~nm}$ (green) to $635 \mathrm{~nm}$ (red) (Biggley et al. 1967; Hastings 1996), and to a large extent depends on the timing of the signaller's peak activity period (Seliger et al. 1964; Biggley et al. 1967; Lall et al. 1980; Hall et al. 2016). Nocturnal lampyrid species typically emit green light that matches the colour of the surrounding vegetation, resulting in a greater amount of the light being reflected from the vegetation, and therefore a greater likelihood of attracting a mate (Seliger et al. 1982a, b). The yellower (higher wavelength) glow of dusk-active species, in turn, is more advantageous during sunsets when the signaller is surrounded by the yellower light of the setting sun. Under such conditions, the yellower glow contrasts with the wavelengths reflected from the surrounding vegetation, resulting in a pronounced signal (Lall et al. 1980; Hall et al. 2016). In this respect, the wavelength variation of bioluminescence in fireflies has presumably developed to enhance the visibility and efficiency of their sexual signals in different signalling environments (Lall et al. 1980; Hall et al. 2016). Thus far, it has 
remained unknown whether glow intensity within a species, as well, is adjustable to geographical variation in light conditions.

As light conditions change with latitude, populations of widely distributed species may be expected to adjust their signals to local light environments to ensure signal visibility. We addressed this question using a nocturnal beetle, the European common glow-worm (Lampyris noctiluca L., Coleoptera: Lampyridae), in which flightless females glow during summer nights to attract flying males (Schwalb 1961; Tyler 2002). Their distribution in Europe extends as far north as central Finland $\left(\mathrm{N} 64^{\circ}\right)$ (information from the Finnish biodiversity info facility, https://laji.fi/). Light conditions may affect detection of female glow, with females needing to attain an adequate contrast with their signalling environment to be visible to mate-searching males. In particular, summer nights at higher latitudes are notably brighter and shorter (for instance, ambient light in the middle of the night can be as high as $5 \mathrm{~lx}$, bright enough to allow reading during the $\sim 4$-h daily dark period in June at $\mathrm{N} 62^{\circ}$ ), and the ambient light also consists of longer wavelengths than in more southern regions. It is expected that such conditions at higher latitudes require brighter glow and/or glow with longer wavelengths (more yellow, as during dusk) for the signal to reach similar detectability as glow signals emitted under light conditions of lower latitudes (Lall et al. 1980; Seliger et al. 1982a, b; Hall et al. 2016).

The aim of this study was to investigate how adult female glow-worms cope with signalling at different latitudes and their light conditions. We expected that brighter summer nights at higher latitudes select for (1) a later emergence of females in summer to avoid glowing when the nights are the brightest, and/or (2) an increased female glow intensity and peak wavelength ( $\lambda_{\max }$, a measure of glow hue, or more generally speaking, colour). Each of these traits can be expected to increase the visibility of females to mate-searching males. We tested these hypotheses by locating glowing females and by measuring their glow intensity, $\lambda_{\max }$, and ambient light intensity, along a latitudinal gradient in Finland.

\section{Materials and methods}

\section{Study species}

The common glow-worm is widely distributed in the northern hemisphere, ranging between latitudes $\mathrm{N} 31^{\circ}$ (central Iran) and N64 ${ }^{\circ}$ (central Finland) (Samin et al. 2018; the Finnish biodiversity info facility, https://aji.fi/). In many areas within this range, including England (Hickmott and Tyler 2011) and southern Finland (personal observations), adults are most active between June and July when summer nights are at their shortest and brightest. During the narrow timeframe when the sun is set, flying males search for females, with the brightest, and thus largest (Hopkins et al. 2015) females having the highest probability of attracting a mate (Tyler 2002; Hopkins et al. 2015; Lehtonen and Kaitala 2020). Females produce their mate attraction glow with chemical chain reactions within a light organ in the tip of their abdomen (Tyler 2002). Once a female has reached its maximum brightness, it glows constantly throughout the dark period (Tyler 2002). The glow has a yellowish green colour, peaking at $546-570 \mathrm{~nm}$ in wavelength (Booth et al. 2004; De Cock 2004; Bird and Parker 2014). Delayed mating is a considerable cost for females because they do not eat as adults (Tyler 2002) and lose eggs until succeeding to mate (Wing 1989; Hopkins 2018). Therefore, good visibility of their mate attraction signal is crucial.

\section{Measurements}

We measured female glow and ambient light at females' chosen glowing spots in June and July of 2017 and 2018. In total, we sampled 11 sites within four separate study areas, along a latitudinal gradient in Finland (Fig. 1). We started searching for glowing females at each site late in the evening, but before the first ones began to glow. Independent of latitude, females typically glowed in open areas, either on a rocky surface (often partly surrounded by lichen, moss, or other vegetation) or hanging from a blade of grass. In 2017, we measured females in the southern sites (study areas A and B in Fig. 1) between the 16th of June and the 9th of July, and in northern sites (study areas C and $\mathrm{D}$ in Fig. 1), where the growing season starts later, between the 10th and the 31st of July. In 2018, we found and measured females starting from the southernmost study sites on the $3 \mathrm{rd}$ of June, and then continued north, keeping up with the progression of summer at different latitudes. We arrived the northernmost study sites on the 24th of June to search for and measure females until the 7th of July, after which we returned to the southern sites and continued measurements there (Table 1). The dark period was shorter, and dawn and dusk lasted longer further north (personal observations, https://www.esrl.noaa. gov/gmd/grad/solcalc/).

Thus far, it has been challenging to collect glow intensity and colour data without handling the insect during the measurements. Moreover, previous measurement procedures have most likely included a considerable risk of measurement biases due to extraneous light (Hall et al. 2016). We successfully introduced a novel method to measure the absolute irradiance of female glow in field conditions (from here on called "glow intensity"). This method allowed us to measure glow intensities of females in their natural mate attraction pose with only a little or no handling of the females, minimising environmental light biases. In particular, we recorded the glow spectra of 85 females in the field over the 2 years (2017: $N=34,2018: N=51)$ using an integrating sphere $50 \mathrm{~mm}$ in diameter (IC-2, StellarNet Inc., USA) fibre-optically connected to a spectrometer (Flame-S, Ocean Optics Inc., USA), controlled by the operating software OceanView (version 1.5.2, Ocean Optics Inc., USA) on a 
Fig. 1 Glow-worm collection and study areas in Finland. In 2017, we collected the data from study areas $\mathrm{A}$ and $\mathrm{D}$, and from all the four study areas in 2018. The distance between the farthest areas is circa $350 \mathrm{~km}$. The data for creating the map was extracted from GADM database (www. gadm.org), version 3.4, in April 2018

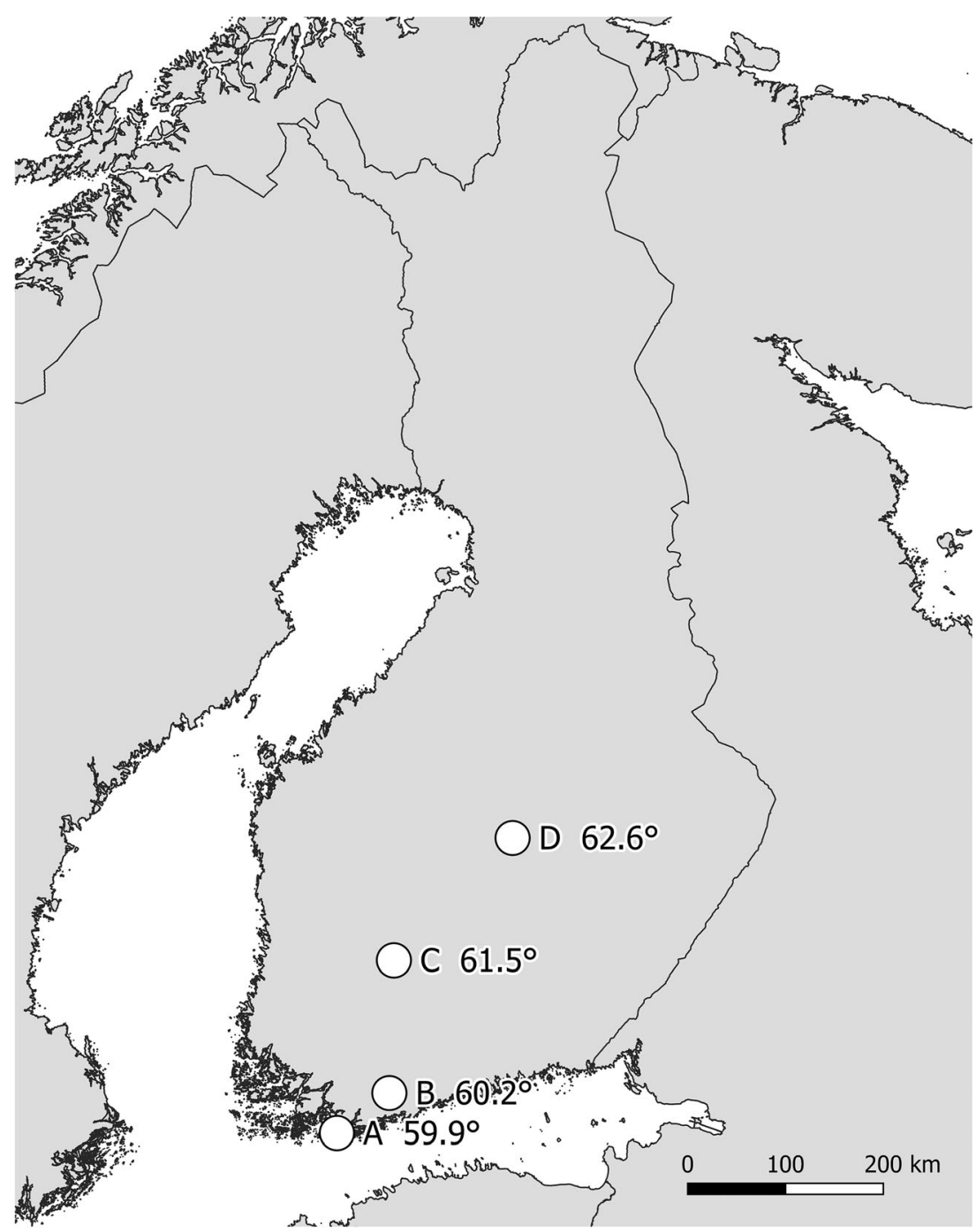

laptop. The integrating sphere with its barium sulphate coating ensures total integration and mixing of the light entering the sphere, producing a highly diffuse reflectance (Fig. 6 in Endler 1990). Its small opening for the object to be measured also blocks direct ambient light from entering the device. These measurements were done on a $24 \mathrm{~cm} \times 32 \mathrm{~cm}$ cardboard platform that was covered with a sheet of white paper and had a $3.0-\mathrm{cm}$-long and $0.5-\mathrm{cm}$-wide white hollow plastic stick protruding through the paper and pointing upwards (Fig. 2).

When we located a glowing female, we placed it gently on the platform next to the stick. If the female did not climb onto the stick, we gently placed the female directly on it. When we found a female that was glowing on grass, moss, or leaf, we took some of the plant material with the female to avoid touching and disturbing it. If it was not practical to remove some of the material the female was glowing on, we moved the female to the platform gently with a plastic spoon. When attracting males, a female raises its abdomen upwards and stays rather still. Therefore, to minimise the possibility of stress from handling, we proceeded with the measurement only after the female had settled down and raised its abdomen. We then lowered the integrating sphere (Fig. 2) so that the female only just disappeared inside (its glow not directed to the photodetector of the collecting optic fibre to avoid measurement error) and initiated the measurement. We discarded the recordings in which the female lowered its abdomen during (or just before) the measurement, as detected with the OceanView software visualisation on the laptop screen, and took a new one.

Each measurement included six scans with an integration period of $0.5 \mathrm{~s}$ (the time over which the spectrometer gathers light during one scan), and the average over the six scans was used in the analyses. When the female glow was too dim to produce a detectable emission spectrum, we increased the integration time to $0.8(N=1), 1.0(N=5)$, or $2.0 \mathrm{~s}(N=1)$. If the glowing intensity was at the border of the equipment's accuracy, we were not able to reliably measure the glow of the individual. This happened mostly at the start of the study period in June in the southernmost study area, likely because night temperatures 
Table 1 Information gathered during female measurements from 11 sites (divided into four study areas A-D) during 2017 and 2018: A = Tvärminne Zoological Station (A1),

Tvärminne Harbour (A2), Bengtsårbryggan (A3), and Öby (A4) sites. B = Lohja's Paloniemi Beach site (B). $\mathrm{C}=$ Kangasala's Paskoluoto (C1), Paskoniemi (C2), Pelisalmi (C3), and Huutijärvi (C4) sites. D = Konnevesi (D1) and Äänekoski (D2) sites. The table provides the numbers of measured females $(N)$, the dates of measurements, the times of day when the females were spotted, and the latitudes of the sites. Temperatures were retroactively provided by the Finnish Meteorological Institute (https://en.ilmatieteenlaitos.fi/), and degree days were calculated from the start of year (the 1st of January) until the day of the measurement (https://www. farmit.net/). Lengths of the dark period were calculated from the apparent sunset to the apparent sunrise (https://www.esrl.noaa. gov/gmd/grad/solcalc/), and are averages over the dates in question, rounded to the nearest $5 \mathrm{~min}$

\begin{tabular}{|c|c|c|c|c|c|c|c|}
\hline Year and site & $N$ & Dates & $\begin{array}{l}\text { Spotting } \\
\text { times }\end{array}$ & Latitude & $\begin{array}{l}\text { Temperature } \\
\left({ }^{\circ} \mathrm{C}\right)\end{array}$ & $\begin{array}{l}\text { Length of the } \\
\text { dark period }\end{array}$ & $\begin{array}{l}\text { Degree } \\
\text { days }\end{array}$ \\
\hline \multicolumn{8}{|l|}{2017} \\
\hline \multirow[t]{2}{*}{$\mathrm{A} 1$} & 2 & 17.6.-19.6. & $0: 30-2: 10$ & 59.842 & $11.9-13.4$ & $5 \mathrm{~h} 10 \mathrm{~min}$ & $218-241$ \\
\hline & 10 & 7.7.-9.7. & $0: 21-1: 45$ & & $9.5-12.2$ & 5 h $35 \mathrm{~min}$ & $389-406$ \\
\hline $\mathrm{A} 2$ & 5 & 16.6 & $0: 25-1: 32$ & 59.839 & $12.5-12.8$ & $5 \mathrm{~h} 15 \mathrm{~min}$ & 208 \\
\hline \multirow[t]{2}{*}{$\mathrm{A} 3$} & 4 & 29.6 & $0: 35-1: 25$ & 59.888 & 15.2 & $5 \mathrm{~h} 15 \mathrm{~min}$ & 321 \\
\hline & 2 & 4. -5.7 & $0: 45-2: 00$ & & $10.7-12.3$ & 5 h $30 \mathrm{~min}$ & $364-372$ \\
\hline A4 & 4 & 6.7.-8.7. & $0: 47-2: 00$ & 59.923 & $8.5-11.2$ & 5 h $35 \mathrm{~min}$ & $381-397$ \\
\hline \multirow[t]{2}{*}{ D1 } & 3 & 10.7 & $0: 37-1: 08$ & 62.697 & 11.1 & $4 \mathrm{~h} 35 \mathrm{~min}$ & 365 \\
\hline & 4 & 27.7.-30.7. & $0: 10-0: 44$ & & $10.2-16.8$ & $6 \mathrm{~h} 10 \mathrm{~min}$ & $519-555$ \\
\hline \multicolumn{8}{|l|}{2018} \\
\hline \multirow[t]{4}{*}{$\mathrm{A} 1$} & 1 & 3.6. & $0: 52$ & 59.843 & 14.1 & $5 \mathrm{~h} 40 \mathrm{~min}$ & 278 \\
\hline & 1 & 11.6 & $1: 10$ & & 12.8 & $5 \mathrm{~h} 20 \mathrm{~min}$ & 337 \\
\hline & 5 & 9.7.-11.7. & $23: 48-2: 10$ & & $14.4-16.3$ & $5 \mathrm{~h} 45 \mathrm{~min}$ & 599-637 \\
\hline & 5 & 15.7.-16.7. & $23: 45-2: 15$ & & $20.1-21.8$ & $6 \mathrm{~h}$ & $695-714$ \\
\hline $\mathrm{A} 2$ & 4 & 5.6.-9.6. & $0: 23-1: 30$ & 59.839 & $6.9-7.3$ & 5 h $30 \mathrm{~min}$ & $301-324$ \\
\hline \multirow[t]{2}{*}{$\mathrm{A} 3$} & 7 & 7.6.-8.6. & $0: 09-1: 50$ & 59.888 & $7.8-11.8$ & 5 h $30 \mathrm{~min}$ & $312-317$ \\
\hline & 3 & 12.7 & $0: 33-1: 20$ & & 17.4 & $5 \mathrm{~h} 45 \mathrm{~min}$ & 648 \\
\hline \multirow[t]{2}{*}{$\mathrm{B}$} & 6 & 10.6 & $23: 54-1: 25$ & 60.266 & $12.0-12.4$ & $5 \mathrm{~h} 10 \mathrm{~min}$ & 390 \\
\hline & 1 & 10.7 & $0: 42$ & & 12.9 & $5 \mathrm{~h} 35 \mathrm{~min}$ & 718 \\
\hline $\mathrm{C} 1$ & 6 & 14.6.-17.6. & $0: 23-1: 45$ & 61.514 & $12.3-17.1$ & $4 \mathrm{~h} 35 \mathrm{~min}$ & 425 \\
\hline $\mathrm{C} 2$ & 1 & 17.6. & $1: 22$ & 61.491 & 16.4 & $4 \mathrm{~h} 30 \mathrm{~min}$ & 461 \\
\hline $\mathrm{C} 3$ & 3 & 16.6 & $0: 15-1: 00$ & 61.465 & $13.4-14.3$ & $4 \mathrm{~h} 35 \mathrm{~min}$ & 448 \\
\hline $\mathrm{C} 4$ & 1 & 16.6 & $1: 43$ & 61.442 & 13.2 & $4 \mathrm{~h} 35 \mathrm{~min}$ & 448 \\
\hline D1 & 3 & 3.7.-4.7. & $1: 05-1: 56$ & 62.617 & $10.9-11.9$ & $4 \mathrm{~h} 15 \mathrm{~min}$ & $516-526$ \\
\hline \multirow[t]{2}{*}{ D2 } & 2 & 24.6 & $1: 23-1: 25$ & 62.663 & 13.8 & $3 \mathrm{~h} 55 \mathrm{~min}$ & 466 \\
\hline & 2 & 7.7. & $0: 20-1: 12$ & & 15.0 & $4 \mathrm{~h} 25 \mathrm{~min}$ & 598 \\
\hline
\end{tabular}

were low, and the female glowing capacity may have been challenged. After the glow measurement, we measured the width of the back shield (the pronotum) with a Vernier calliper, as it is a good proxy of female body size (Hopkins et al. 2015; Borshagovski et al. 2019). We measured each female only once and then returned it to its original spot of collection.
Fig. 2 Equipment for measuring female glow. A computer with the operating software OceanView (version 1.5.2, Ocean Optics Inc., USA) was connected to the spectrometer and integrating sphere (black cube). When a female was hanging from the stick on the measuring platform, and raised its glowing abdomen, we lowered the integrating sphere onto the female and took the measurements

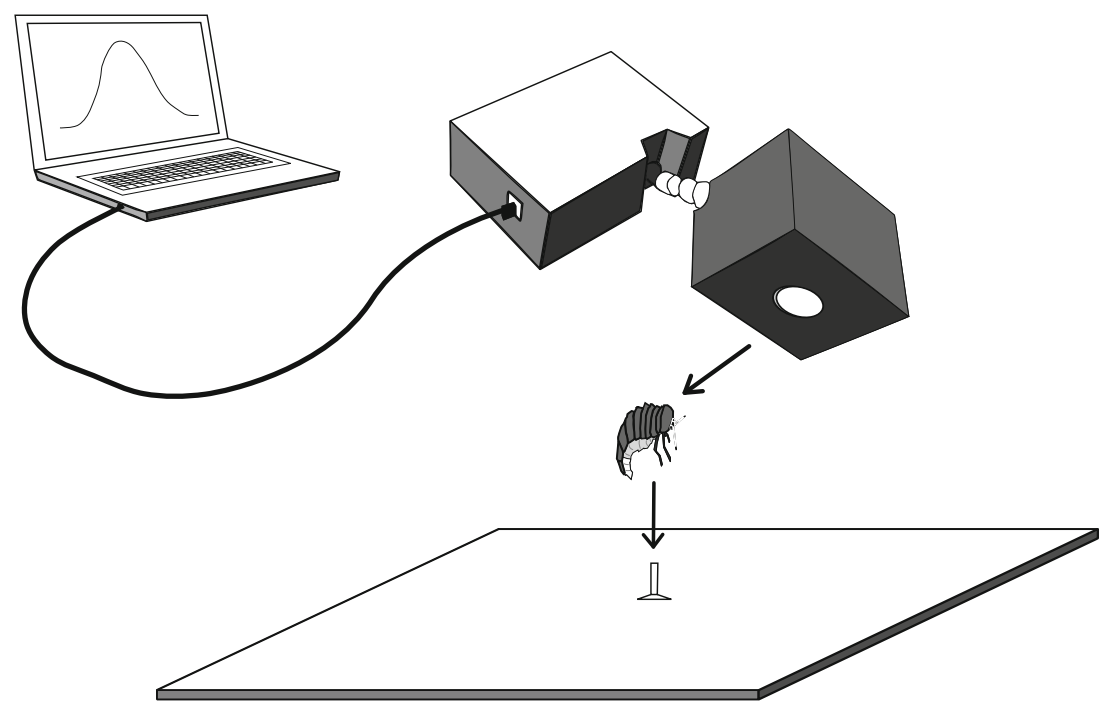


The measurement of the ambient light where the female was found was conducted immediately after the measurement of the pronotum. We used the same devices as with female glow measurements but replaced the integrating sphere with a cosine-corrected irradiance probe (CC-3-UV-S, Ocean Optics Inc., USA), which gathers light from a $180^{\circ}$ angle (Fig. 5 in Endler 1990; Online Resource 1, Fig. S1). The spectrometer was oriented so that the cosine-corrected irradiance probe was pointing upwards at the spot where the female had glowed. We positioned the laptop and measurers as far away from the measuring spot as allowed by the $1.5-\mathrm{m}$ cable connecting the laptop and spectrometer, to avoid light reflecting from the measurers and affecting the measurements. Each ambient light measurement included three scans with an integration time of $3 \mathrm{~s}$, from which we set the programme to calculate the average values. If the ambient light was too dim to produce a detectable emission spectrum, for instance when a female was glowing in a dense bush, we increased the integration time to $4.0(N=12), 5.0$ $(N=4), 6.0(N=2)$, or $10.0 \mathrm{~s}(N=1)$. Such sensitivity adjustments are not expected to impact the result of the measurement. We successfully measured the ambient light level $N=75$ times. We did not measure it when it was too dark for our measurement device to produce a reliable measurement. In addition, when the female glowed close to a streetlamp $(N=6)$, ambient light emission spectra peaked at significantly higher wavelengths than under natural light, and we therefore excluded these ambient light measurements from the analyses.

For the analyses of light data, we produced a script for MATLAB R2016b (the MathWorks Inc., USA). In brief, each data pair of female glow and ambient light was processed as follows. Each measurement was assessed between 300 and $700 \mathrm{~nm}$, averaged and low-pass filtered (Savitzky-Golay, S$\mathrm{G}$ ), and depicted in emission spectrum figures (Fig. 3 for the female spectrum, and Fig. S2 in Online Resource 1 for the ambient light spectrum). If some of the six scans of a female resulted in notably lower glow intensity values than the rest (potentially biasing the intensity measurement result), we discarded them, one at a time, until the average of the remaining intensity values equated $\geq 85 \%$ of the highest intensity value for that female $(N=6)$. To determine an accurate peak location of the female glow spectrum ( $\lambda_{\max }$, measure of hue/ colour), a skewed Gaussian fitting was applied. Absolute irradiance of the glow in photons/s, and the ambient light in photons/s (also in lux, to enable comparisons with previous findings) were calculated from the surface area of the Gaussian fit and over the 300-700-nm S-G-filtered average spectrum, respectively (Online Resource 2).

We calibrated the integrating sphere before field measurements with a light source, LS-1-CAL (Ocean Optics Inc., USA). The cosine-corrected irradiance probe was calibrated by Ocean Optics with a standard light source. Ideally, the equipment should be calibrated before every measurement. However, due to the logistic challenges it would have caused under field

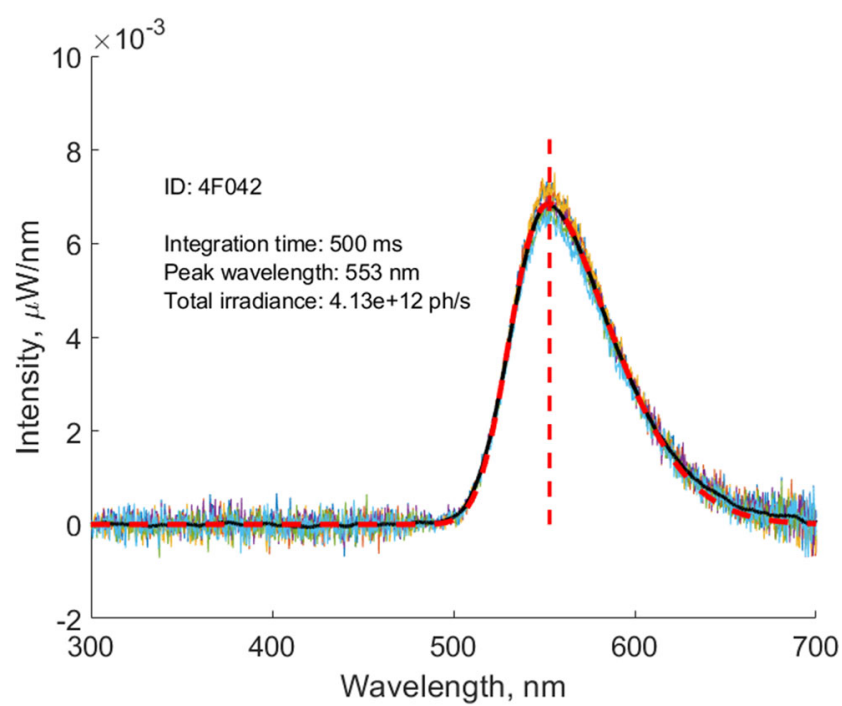

Fig. 3 Peak wavelength $\left(\lambda_{\max }\right)(\mathrm{nm})$ and total irradiance (photons/s) were calculated with MATLAB R2016b (the MathWorks Inc., USA) from the Skewed Gaussian fitting curve (thick, broken curve). Average $\mu \mathrm{W} / \mathrm{nm}$ values (thick, black curve; $\mu \mathrm{W} / \mathrm{nm}$ is the default unit of the measurement software) were calculated and drawn from the six scans (thin, saw-toothed curves) taken from a single female glow-worm with 500-ms integration time. Small differences between the intensity curves are a result of the female moving slightly inside the integrating sphere during the measurement. Glow spectrum ranged typically between 500 and $700 \mathrm{~nm}$, with circa 70-nm full width at half maximum

conditions, and its time-consuming nature, we first conducted several test measurements by reassembling the measurement equipment with a calibration against a stable light source to see if any significant differences would appear in the results. Because we did not find any significant shifts in the results, we produced all the measurements for both study years with the same calibration, conducted just before the 2017 field season.

Overall, the dataset for our analyses included 85 female glow intensities and $\lambda_{\max }$ values, 75 ambient light intensities, 74 ambient $\lambda_{\max }$ values, and 81 female size measurements. In addition, for each of these measurements, we also retrospectively assigned a temperature value from the data of the Finnish Meteorological Institute (available for each hour at https://en.ilmatieteenlaitos. fi/). Because temperature values are not additive quantities (in relation to female glow intensity and $\lambda_{\max }$ ), we used temperature as a categorical variable in the data analysis by classifying the temperature values at the time of glow measurements into four categories, (1) < $10{ }^{\circ} \mathrm{C}$, (2) $10-13.9^{\circ} \mathrm{C}$, (3) $14-17.9^{\circ} \mathrm{C}$, and (4) $\geq 18^{\circ} \mathrm{C}$ (the temperatures for each site are given in Table 1).

\section{Statistical analyses}

We conducted all analyses with $\mathrm{R}$ software version 3.6.1 (The R Foundation for Statistical Computing, http://www.r-project. org). To analyse the factors affecting female glow (intensity and peak wavelength), we performed two linear models (LM). For this purpose, we tested the data for normality with 
Shapiro-Wilk tests, and applied logarithmic transformations when normality was not otherwise met. In addition, we visually checked model assumptions of normally distributed errors and homoscedasticity with quantile-quantile plots of residuals and scale-location plots. The first model included female glow intensity (logarithmic) as the response variable, and latitude, female body size (pronotum width), ambient light intensity (logarithmic), year, and temperature (categorical) as explanatory variables. The initial model also included all two-way interactions between the explanatory variables. We then simplified the model with backward elimination of nonsignificant interactions, having $P=0.10$ as the threshold. The model objects produced by the final linear models were assessed with the ANOVA function in $\mathrm{R}$. The second model included peak wavelength ( $\lambda_{\max }$, its hue/colour) of female glow as the response variable, and latitude, female body size, year, and temperature category as explanatory variables. In other respects, the model was treated as above. To further assess any relationships between our key variables, we conducted a correlation test between the two response variables, latitude and female body size, and a partial correlation test between latitude and glow intensity while controlling for female body size.

We did not use dates of glow measurements and times of the day in the models because environmental conditions and developmental stages of glow-worms are likely to be very different between southern and northern study areas at a certain time. As much as possible, we attempted to collect data during the peak glowing period, independent of latitude. Measurement dates and times are provided in Table 1.

\section{Results}

\section{Light conditions along the latitudinal gradient}

The ambient light conditions were highly different for females glowing at the different locations in Finland. The intensity of ambient light (over both study years) during glow measurements was circa nine times higher in the northernmost study area $\left(\mathrm{N} 62.62^{\circ} ; 1.02 \times 10^{13} \pm\right.$ $1.94 \times 10^{12}$ photons $/ \mathrm{s}, 2.40 \pm 0.46 \mathrm{~lx}[$ mean $\pm \mathrm{SE}], N=$ $13)$, than in the southernmost study area (N59.86 $1.16 \times 10^{12} \pm 1.59 \times 10^{11}$ photons/s, $0.27 \pm 0.039 \mathrm{~lx}, N=$ 45). The intensity of the brightest ambient light, in which we found glowing females, was $2.29 \times 10^{13}$ photons/s (5.37 lx). Despite the challenges ambient light conditions pose to the visibility of female glow in higher latitudes, we found females glowing in the northernmost study area even on the 24th of June, the brightest time of summer (Table 1). Hence, the results suggest that females do not avoid glowing during the period of the brightest summer nights.

\section{Female brightness}

All the considered interaction terms were nonsignificant $(P>0.10)$. The final model with the main effects showed that female glow intensity increased significantly with both latitude and female size (Table 2; Figs. 4 and 5), indicating that larger females were brighter, and that females were brighter (relative to their size) in the north. Indeed, when controlling for female body size, there was a statistically significant positive partial correlation between latitude and female brightness (Pearson $r_{\text {partial }}=0.276, t_{78}=2.536, P=0.013$ ). Female size also increased with latitude (Pearson correlation test: $r=$ 0.367, $N=81, P<0.001$; Fig. 6). Over all study sites, the mean female glow intensity in 2017 was $3.50 \times 10^{12} \pm$ $5.36 \times 10^{11}$ photons/s (range: from $2.57 \times 10^{11}$ to $1.50 \times 10^{13}$ photons/s, $N=34$ ), and in 2018 , it was $3.03 \times 10^{12} \pm 2.79 \times$ $10^{11}$ photons/s (range: from $7.8 \times 10^{11}$ to $8.44 \times 10^{12}$ photons/ $\mathrm{s}, N=51)$. Glow intensities did not significantly differ between the 2 years (Table 2). In addition, neither intensity of ambient light nor temperature significantly affected the intensity of female glow (Table 2).

\section{Colour of female glow}

All interaction terms were again found to be nonsignificant $(P>0.10)$. In contrast to the glow intensity, neither the latitude nor female size significantly affected peak wavelength $\left(\lambda_{\max }\right)$ (Table 2; Online Resource 1, Fig. S3). However, $\lambda_{\max }$ increased significantly with the temperature category (Table 2; Fig. 7), and was, on average, greater in 2017 than in 2018 $(553.0 \mathrm{~nm} \pm 0.1 \mathrm{~nm}$, range: from 551.8 to $554.6 \mathrm{~nm}, N=34$; $552.4 \mathrm{~nm} \pm 0.1 \mathrm{~nm}$, range: from 550.0 to $554.4 \mathrm{~nm}, N=51$, respectively). These results may be considered surprising in

Table 2 Results of the final linear models on female glow intensity and peak wavelength: degrees of freedoms (df), $F$ values and $P$ values

\begin{tabular}{llll}
\hline & df & $F$ & $P$ \\
\hline Glow intensity & & & \\
Latitude & 1 & 17.031 & $<0.001$ \\
Body size & 1 & 17.530 & $<0.001$ \\
Ambient light & 1 & 0.0013 & 0.97 \\
Year & 1 & 2.670 & 0.11 \\
Temperature category & 3 & 0.601 & 0.62 \\
Residuals & 64 & & \\
Peak wavelength & & & 0.91 \\
Latitude & 1 & 0.014 & 0.088 \\
Body size & 1 & 2.995 & $<0.001$ \\
Year & 1 & 25.801 & $<0.001$ \\
Temperature category & 3 & 9.253 & \\
Residuals & 74 & & \\
\hline
\end{tabular}




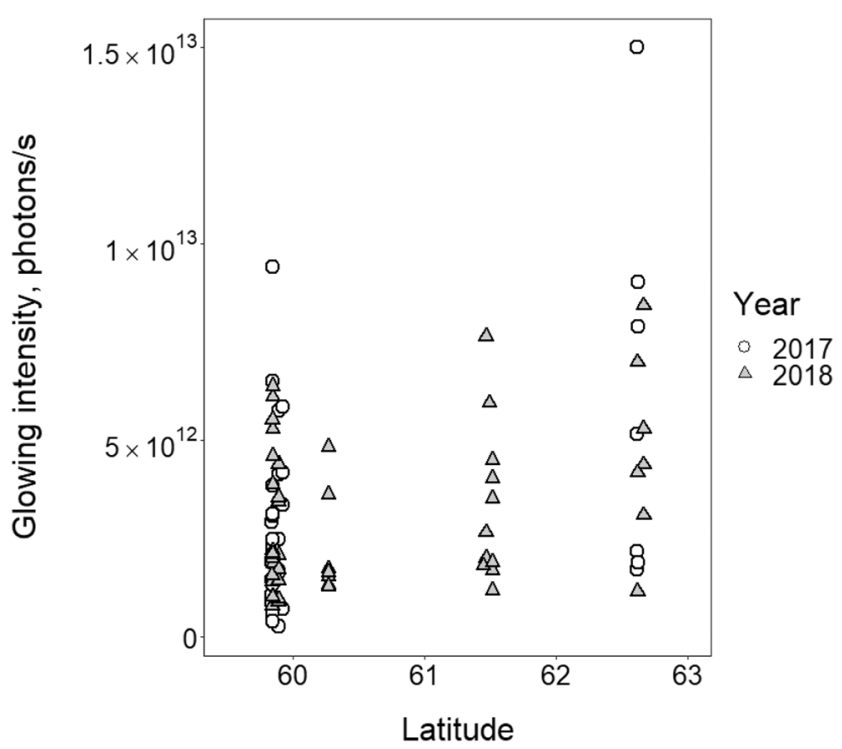

Fig. 4 Female glow intensities along the latitudinal gradient in summers of $2017(N=34, r=0.41$; white circles $)$ and $2018(N=51, r=0.24$; grey triangles)

the sense that we measured, on average, higher temperatures in $2018\left(13.7^{\circ} \mathrm{C} \pm 0.5^{\circ} \mathrm{C}\right.$, the four temperature categories: $\left.N_{1}=6, N_{2}=22, N_{3}=18, N_{4}=5\right)$ than in $2017\left(11.9^{\circ} \mathrm{C} \pm\right.$ $0.3{ }^{\circ} \mathrm{C}, N_{1}=6, N_{2}=23, N_{3}=5, N_{4}=0$; Table 1), and therefore, female $\lambda_{\max }$ would have been expected to be, if anything, higher in 2018 than in 2017.

\section{Discussion}

We found that female glow-worms were glowing in our most northern study area $\left(\mathrm{N} 62.62^{\circ}\right)$ during midsummer nights,

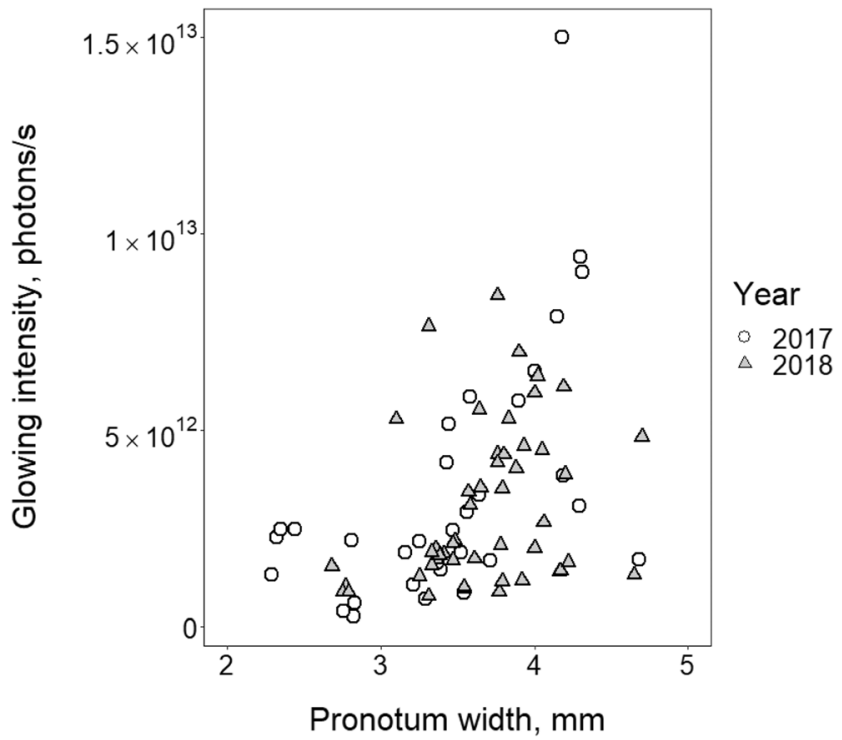

Fig. 5 The relationship between female size (pronotum width, $\mathrm{mm}$ ) and female glowing intensity in $2017(N=32, r=0.56$; white circles) and $2018(N=49, r=0.31$; grey triangles $)$

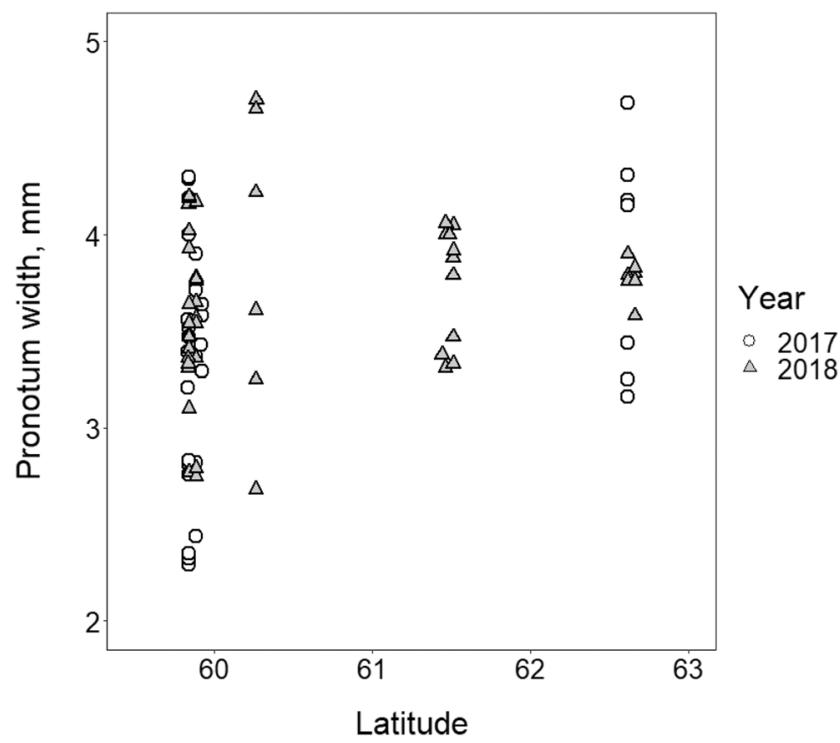

Fig. 6 Female size (pronotum width, $\mathrm{mm}$ ) along the latitudinal gradient in $2017(N=32, r=0.37$; white circles $)$ and $2018(N=49, r=0.18$; grey triangles)

which suggests that they attract males even during the brightest time of the year, in the part of their range where summer nights are the least dark. Our results also show that glow intensity and body size of females increased with latitude (that is, towards north). Larger body size and greater glow intensity at higher latitudes presumably allow sufficient visibility to mate-searching males in the challenging signalling environment (relatively bright nights).

Given that both female size and other factors that increase glow intensity are expected to increase mate attraction success (e.g. Hopkins et al. 2015; Lehtonen and Kaitala 2020), it is reasonable to ask what prevents females in the lower latitude sites from growing to a larger size and producing a brighter glow, similar to females at the northern sites. Most

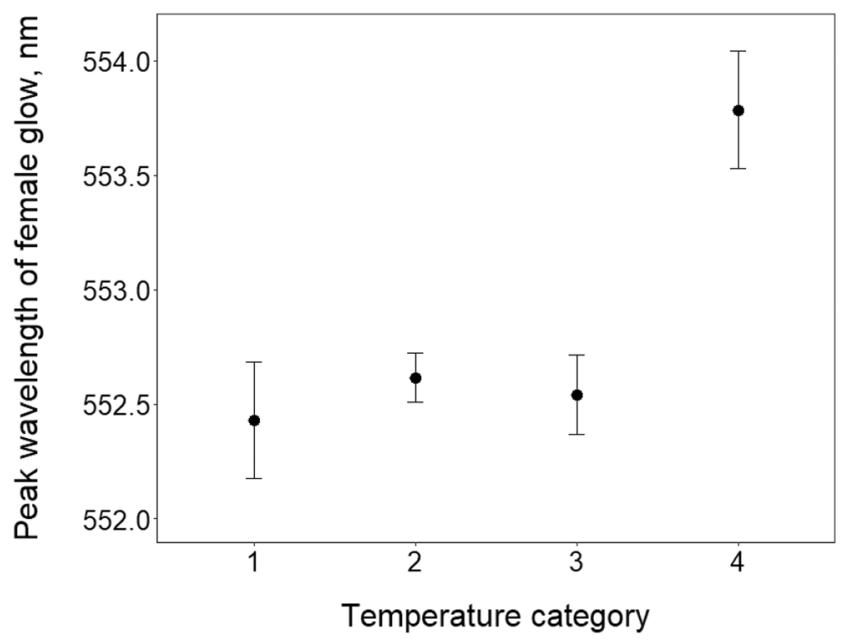

Fig. 7 The average peak wavelength $\left(\lambda_{\max }\right)$ of female glow in each temperature category $\left((1)<10{ }^{\circ} \mathrm{C},(2) 10-13.9^{\circ} \mathrm{C}\right.$, (3) $14-17.9^{\circ} \mathrm{C}$, and (4) $\geq 18^{\circ} \mathrm{C}$ ) with standard errors, including data from both study years 
importantly, larger size and other potentially costly factors that help to attain a brighter glow should provide a higher selection advantage in the brighter light conditions of higher latitudes. However, growing seasons are also shorter in the north, which makes larger body size potentially even costlier to reach there than in more southern regions. Hence, individuals in higher latitudes seem to experience a steeper trade-off between the costs of growing (due to the shorter growing seasons) and visibility (larger body size needed). Given that there is a clear relationship between development time and body size in many species, one way of reaching a larger adult body size is to prolong development time (Roff 1992, 2000), with development time and body size often correlating positively (Masaki 1967; Roff 1992). Therefore, insects are expected to prolong their development time, when feasible, to gain larger size and greater fecundity (Honêk 1993). At higher latitudes, prolonging the time available for growth may require spending at least one additional year in the larval stage, with an additional risky winter diapause. In other words, females presumably face a trade-off between the costs of postponing maturation (by at least one full year so that pupation occurs during the summer breeding season) and gaining a larger body size during that time, which ensures higher glow intensity and visibility to mate-searching males. Our results indicate that the way females respond to this trade-off depends on the latitude of their signalling site. Some animals can compensate for the shorter available development time at higher latitudes by growing at a faster rate (Abrams et al. 1996; Arendt 1997; Nylin and Gotthard 1998). Indeed, seasonal environments favour plasticity in developmental time (Nylin and Gotthard 1998). However, a shorter time available for the development does not typically result in greater body size (Abrams et al. 1996), and therefore does not explain our result of females being larger at higher latitudes. To gain further insights into the mechanisms that cause the positive association between adult female size and latitude, and to better understand the complex relationship between body size, development time, and growth rate, we encourage future studies that involve rearing glow-worms from populations located at a range of different latitudes under a common garden setup.

Similarly, the timing of maturation within a summer is likely to be subject to trade-offs, especially regarding the properties of the signalling environment, mate availability, and temperatures suitable for maturation and mate attraction. For instance, in many species, the first individuals to emerge as adults face decreased competition, but these individuals are often smaller in size (Morbey and Ydenberg 2001), which may be costly to attractiveness or fecundity. In glow-worms, a small body size has multiple costs to females. First, small females have a dimmer glow, and they therefore attract males less easily (Hopkins et al. 2015). Second, fecundity costs due to delays in mating seem to be higher for small females of these capital breeders (Hopkins 2018). Hence, small size poses a risk of not attracting a mate quickly, and this delay in mating may even result in a complete reproductive failure quicker than it does for larger females. Theoretically, these costs could, at least partly, be mitigated by postponing maturation to a time after the brightest midsummer nights. The fact that females did not do so, even at the higher latitude sites, suggests that it is not feasible. For instance, postponing maturation at higher latitudes might leave too small a timewindow to ensure successful mating, before the short season is over. Therefore, factors other than the challenges of glowing under bright ambient light conditions seem to be the main drivers of the timing of maturation.

Although female glow was brighter at higher latitudes, where nights were more illuminated, female glow intensity was not significantly linked to the intensity of ambient light at the measurement spot. In other words, within the study areas, individual females did not adjust their glow intensity to the immediate ambient brightness. Therefore, glow intensity does not seem to be a trait that is quick to control at an individual level. Previous findings are in accordance with this finding: females do not adjust their glow intensity between nights to respond to the time spent unmated, and competition does not affect the onset of glow (Baudry et al. unpublished data). Nevertheless, it remains unclear to which extent increasing glow intensity and body size towards higher latitudes are genetically based or represent phenotypic plasticity, as both types of responses can drive latitudinal body size differences in ectotherms (e.g. Mousseau and Roff 1989; James et al. 1997; Blanckenhorn and Demont 2004).

Interestingly, even when body size was controlled for, glow intensity increased with latitude, indicating that body size is not the only factor driving glow intensity, and that females have additional means to glow brighter at higher latitudes. Currently, the exact mechanism allowing females to do so is not known, providing fascinating avenues for further investigation, preferably using laboratory-reared individuals. We also note that, besides night brightness, other factors may differ with latitude, potentially contributing to the development and quality of the glow signal. We do not have data on the variation in soil quality or food availability, for instance. Therefore, while we show that the female phenotype (glow and size) matches with the requirements of the night-time conditions that are defined by latitude, further research is needed to investigate the full range of factors that might contribute to this pattern.

In contrast to the glow intensity, the peak wavelength $\left(\lambda_{\max }\right.$, measure of hue/colour) of female glow did not covary with latitude. We offer the following two hypotheses that may explain the lack of a significant relationship. First, the effect of latitude on colour may become apparent only in a very large-scale study, that is, when measuring female glow spectra over a wider latitudinal range. In this regard, it is worth noting that although the latitude range used in the current study did not reveal a significant 
gradient in glow colour, it did so regarding female size and brightness. Second, if male mate searching is not sensitive to small differences in $\lambda_{\max }$ values, the exact colour of female glow may not be under selective pressure, indicating that latitudedependent changes in ambient wavelength composition are less important in sexual signalling. Glow-worms may, indeed, adjust to ambient light more easily, or efficiently, in other ways than by changing glow colour, for example by altering some aspects of their signalling behaviour.

The temperature category did not significantly explain variation in female brightness. However, in accordance with glow intensity increasing with temperature to a certain optimum in in vitro experiments (Ueda et al. 1994), we did notice that females could not glow at their usual intensity during the coldest nights (approximately below $7{ }^{\circ} \mathrm{C}$ ). In contrast to brightness, the $\lambda_{\max }$ of females' bioluminescent light was linked to temperature. This is also in accordance with earlier in vivo and in vitro experiments showing that an increase in temperature shifts the $\lambda_{\max }$ towards longer wavelengths, that is, towards the yellow colour (Hastings 1996; Rabha et al. 2017). As with the colour of the glow-worm glow, firefly flash signalling patterns - which have a significant role in mate attraction and species recognition (Lewis and Cratsley 2008) - are also affected by temperature (Sharma et al. 2016; Rabha et al. 2017). Interestingly, despite the mean temperature being higher in 2018, the average $\lambda_{\max }$ was significantly lower (just the opposite of what the temperature difference would have led us to expect). This could be a result of other factors besides temperature (potentially involving physiological restrictions on light production) affecting the $\lambda_{\max }$. We note that the small $(\sim 1 \mathrm{~nm})$ between-year difference in $\lambda_{\max }$ is unlikely to affect mate search or have other biological relevance. While some day-active insects may be able to discriminate such fine-tuned colour differences (Koshitaka et al. 2008; Telles et al. 2016), the ability for such precise colour discrimination is unlikely for night-active species. Moreover, the spectrum width of the female glow is so wide that small peak differences are even less likely to be detectable.

In conclusion, female sexual signalling was found to be related to its environmental light conditions. In addition, females in the most northern sites were found to attract males even during midsummer nights, despite the challengingly bright night-time conditions. Hence, our results emphasise how a species' signalling environment can promote regional differences in life-history traits and sexual signals, which, in turn, may contribute to population differences through sexual selection. These findings also highlight the potential of nocturnal animals that engage in visual signalling to partially adapt to the increasingly common light pollution over time.

Supplementary Information The online version contains supplementary material available at https://doi.org/10.1007/s00265-020-02927-9.
Acknowledgements We thank the personnel of Tvärminne Zoological Station and Konnevesi Research Station for facilities and assistance; Esa-Ville Immonen, Sami Saarenpää, Otso Valkeeniemi, and Jouni Valkeeniemi for helping with the experiment; Ulrika Candolin, Alexander Borshagovski, and Antti Yrjölä for valuable advice and study material; and Maria-Elena Bernal for proofreading the text. We are also grateful to anonymous reviewers for their constructive comments and suggestions.

Author contributions $\mathrm{AMB}$ and $\mathrm{AK}$ designed the experiments. AMB, assisted by TKL, performed the field experiments. PS purchased and prepared the measuring devices, developed the code for MATLAB, and assisted with the use of MATLAB. AMB and TKL carried out the statistical analyses. AMB wrote the first draft of the manuscript with all authors contributing to its preparation.

Funding Open access funding provided by University of Oulu including Oulu University Hospital. The work was funded by the Academy of Finland (grant number \#294664 to AK, TKL and AMB) and Emil Aaltonen Foundation (AMB).

Data availability The data generated and analyzed for this study is available in the electronic supplementary materials.

\section{Compliance with ethical standards}

Conflict of interest The authors declare that they have no conflict of interest.

Open Access This article is licensed under a Creative Commons Attribution 4.0 International License, which permits use, sharing, adaptation, distribution and reproduction in any medium or format, as long as you give appropriate credit to the original author(s) and the source, provide a link to the Creative Commons licence, and indicate if changes were made. The images or other third party material in this article are included in the article's Creative Commons licence, unless indicated otherwise in a credit line to the material. If material is not included in the article's Creative Commons licence and your intended use is not permitted by statutory regulation or exceeds the permitted use, you will need to obtain permission directly from the copyright holder. To view a copy of this licence, visit http://creativecommons.org/licenses/by/4.0/.

\section{References}

Abrams PA, Leimar O, Nylin S, Wiklund C (1996) The effect of flexible growth rates on optimal sizes and development times in a seasonal environment. Am Nat 147:381-395

Alexander RD (1962) Evolutionary change in cricket acoustical communication. Evolution 16:443-467

Andersson MB (1994) Sexual selection. Princeton University Press, Princeton

Arendt JD (1997) Adaptive intrinsic growth rates: an integration across taxa. Q Rev Biol 72:149-177

Bateson P (1983) Mate choice. Cambridge University Press, Cambridge

Bernard GD, Remington CL (1991) Color vision in Lycaena butterflies: spectral tuning of receptor arrays in relation to behavioral ecology. Proc Natl Acad Sci U S A 88:2783-2787

Biggley WH, Lloyd JD, Seliger HH (1967) The spectral distribution of firefly light II. J Gen Physiol 50:1681-1692 
Bird S, Parker J (2014) Low levels of light pollution may block the ability of male glow-worms (Lampyris noctiluca L.) to locate females. J Insect Conserv 18:737-743

Blanckenhorn WU, Demont M (2004) Bergmann and converse Bergmann latitudinal clines in arthropods: two ends of a continuum? Integr Comp Biol 44:413-424

Booth D, Stewart AJA, Osorio D (2004) Colour vision in the glow-worm Lampyris noctiluca (L.) (Coleoptera: Lampyridae): evidence for a green-blue chromatic mechanism. J Exp Biol 207:2373-2378

Borshagovski A-M, Baudry G, Hopkins J, Kaitala A (2019) Pale by comparison: competitive interactions between signaling female glow-worms. Behav Ecol 30:20-26

Bowmaker JK (2008) Evolution of vertebrate visual pigments. Vis Res 48:2022-2041

Bradshaw WE, Holzapfel CM (2010) Light, time, and the physiology of biotic response to rapid climate change in animals. Annu Rev Physiol 72:147-166

Brumm H (2004) The impact of environmental noise on song amplitude in a territorial bird. J Anim Ecol 73:434-440

Cole GL (2013) Lost in translation: adaptation of mating signals in changing environments. Springer Sci Rev 1:25-40

Cronin TW, Järvilehto M, Weckström M, Lall AB (2000) Tuning of photoreceptor spectral sensitivity in fireflies (Coleoptera: Lampyridae). L Comp Physiol A 186:1-12

Cronin TW, Johnsen S, Marshall J, Warrant E (2014) Visual Ecology. Princeton university press, Princeton

De Cock R (2004) Larval and adult emission spectra of bioluminescence in three European firefly species. Photochem Photobiol 79:4-7

Endler JA (1990) On the measurement and classification of colour in studies of animal colour patterns. Biol J Linn Soc 41:315-352

Endler JA (1991) Variation in the appearance of guppy colour patterns to guppies and their predators under different visual conditions. Vis Res 31:587-608

Endler JA (1992) Signals, signal conditions, and the direction of evolution. Am Nat 139:125-153

Endler JA (1993a) Some general comments on the evolution and design of animal communication systems. Philos Trans R Soc Lond B 340: 215-225

Endler JA (1993b) The colour of light in forests and its implications. Ecol Monogr 63:1-27

Endler JA (2000) Evolutionary implications of the interaction between animal signals and the environment. In: Espmark Y, Amundsen T, Rosenqvist G (eds) Animal Signals: Signalling and signal design in animal communication. Tapir Academic Press, Trondheim, Norway, pp. 11-46

Endler JA, Basolo AL (1998) Sensory ecology, receiver biases and sexual selection. Trends Ecol Evol 13:415-420

Fleishman LJ (1986) Motion detection in the presence and absence of background motion in an Anolis lizard. J Comp Physiol A 159:711720

Gamble S, Lindholm AK, Endler JA, Brooks R (2003) Environmental variation and the maintenance of polymorphism: the effect of ambient light spectrum on mating behaviour and sexual selection in guppies. Ecol Lett 6:463-472

Hall DW, Sander SE, Pallansch JC, Stanger-Hall KF (2016) The evolution of adult light emission colour in North American fireflies. Evolution 70:2033-2048

Hansson L, Becares E, Fernández-Aláez M, Fernández-Aláez C, Kairesalo T, Miracle MR, Romo S, Stephen D, Vakkilainen K, Van De Bund W, Van Donk E, Balayla D, Brian M (2007) Relaxed circadian rhythm in zooplankton along a latitudinal gradient. Oikos 116:585-591

Hastings W (1996) Chemistries and colours of bioluminescent reactions: a review. Gene 173:5-11
Hickmott W, Tyler J (2011) Seasonal variation in the female display period of the glow-worm Lampyris noctiluca L. (Coleoptera: Lampyridae). Lampyrid 1:14-21

Honêk A (1993) Intraspecific variation in body size and fecundity in insects: a general relationship. Oikos 66:483-492

Hopkins J (2018) The costs and consequences of female sexual signals. Dissertation, University of Oulu, Finland

Hopkins J, Baudry G, Candolin U, Kaitala A (2015) I'm sexy and I glow it: female ornamentation in a nocturnal capital breeder. Biol Lett 11: $8-11$

James AC, Azevedo RBR, Partridge L (1997) Genetic and environmental responses to temperature of Drosophila melanogaster from a latitudinal cline. Genetics 146:881-890

Jennions MD, Petrie M (1997) Variation in mate choice and mating preferences: a review of causes and consequences. Biol Rev 72: 283-327

Koshitaka H, Kinoshita M, Vorobyev M, Arikawa K (2008) Tetrachromacy in a butterfly that has eight varieties of spectral receptors. Proc R Soc B 275:947-954

Lall AB, Seliger HW, Biggley WH, Lloyd JE (1980) Ecology of colours of firefly bioluminescence. Science 210:560-562

Leal M, Fleishman LJ (2002) Evidence for habitat partitioning based on adaptation to environmental light in a pair of sympatric lizard species. Proc R Soc Lond Ser B 269:351-359

Leal M, Fleishman LJ (2004) Differences in visual signal design and detectability between allopatric populations of Anolis lizards. Am Nat 163:26-39

Lehtonen TK, Kaitala A (2020) Leave me alone: solitary females attract more mates in a nocturnal insect. Behav Ecol 31:1040-1045

Lewis SM, Cratsley CK (2008) Flash signal evolution, mate choice, and predation in fireflies. Annu Rev Entomol 53:293-321

Lythgoe JN, Partridge JC (1989) Visual pigments and the acquisition of visual information. J Exp Biol 146:1-20

Masaki S (1967) Geographic variation and climatic adaptation in a field cricket (Orthoptera: Gryllidae). Evolution 21:725-741

McComb DM, Frank TM, Hueter RE, Kajiura SM (2010) Temporal resolution and spectral sensitivity of the visual system of three coastal shark species from different light environments. Physiol Biochem Zool 83:299-307

Mills AM (2008) Latitudinal gradients of biologically useful semi-darkness. Ecography 31:578-582

Morbey YE, Ydenberg RC (2001) Protandrous arrival timing to breeding areas: a review. Ecol Lett 4:663-673

Mousseau TA, Roff DA (1989) Adaptation to seasonality in a cricket: patterns of phenotypic and genotypic variation in body size and diapause expression along a cline in season length. Evolution 43: $1483-1496$

Nylin S, Gotthard (1998) Plasticity in life-history traits. Annu Rev Entomol 43:63-83

Otte D (1974) Effects and functions in the evolution of signalling systems. Annu Rev Ecol Syst 5:385-417

Rabha MM, Sharma U, Goswami A, Gohain BA (2017) Bioluminescence emissions of female fireflies of the species Luciola praeusta. J Photochem Photobiol B 170:134-139

Roff DA (1992) The evolution of life histories: theory and analysis. Routledge, Chapman and Hall, New York

Roff DA (2000) Trade-offs between growth and reproduction: an analysis of the quantitative genetic evidence. J Evol Biol 13:434-445

Rowe C (1999) Receiver psychology and the evolution of multicomponent signals. Anim Behav 58:921-931

Ryan MJ (1990) Sexual selection, sensory systems, and sensory exploitation. Oxf Surv Evol Biol 7:157-195

Samin N, Háva J, Otero JC, Hawkeswood TJ, Iêdryczkowski WB, Kubisz D, Sakenin H, Bunalski M (2018) New record and new distributional data of beetles of Iran (Insecta, Coleoptera). Boln Asoc Esp Ent 42:259-274 
Schwalb HH (1961) Beiträge zur Biologie der einheimischen Lampyriden Lampyris noctiluca Geoffr. und Phausis splendidula Lec. und experimentelle Analyse ihres Beutefang- und Sexualverhaltens. Zool Jb Syst 88:399-550

Seliger HH, Buck JB, Fastie WG, McElroy WD (1964) The spectral distribution of firefly light. J Gen Physiol 48:95-104

Seliger HH, Lall AB, Lloyd JE, Biggley WH (1982a) The colours of firefly bioluminescence-I. Optimization model. Photochem Photobiol 36:673-680

Seliger HH, Lall AB, Lloyd JE, Biggley WH (1982b) The colours of firefly bioluminescence II. Experimental evidence for the optimization model. Photochem Photobiol 36:681-688

Sharma U, Goswami A, Rabha MM, Barua AG (2016) In vivo bioluminescence emissions of the firefly Luciola praeusta at low temperatures. J Photochem Photobiol B 161:383-386

Shieh B, Liang SH, Liao CY, Chiu YW (2017) Song frequency correlates with latitude and individual body size in the cicada Mogannia formosana Matsumura (Hemiptera: Cicadidae). Acta Ethol 20: $147-155$
Smit JAH, Loning H, Ryan MJ, Halfwerk W (2019) Environmental constraints on size-dependent signalling affects mating and rival interactions. Behav Ecol 30:724-732

Telles FJ, Kelber A, Rodríguez-Gironés MA (2016) Wavelength discrimination in the hummingbird hawkmoth Macroglossum stellatarum. J Exp Biol 219:553-560

Tyler J (2002) The glow worm. Lakeside Printing Ltd., Sevenoaks

Ueda I, Shinoda F, Kamaya H (1994) Temperature-dependent effects of high pressure on the bioluminescence of firefly luciferase. Biophys $\mathrm{J}$ 66:2107-2110

Wing SR (1989) Energetic costs of mating in a flightless female firefly, Photinus collustrans (Coleoptera: Lampyridae). J lnsect Behav 2: 841-847

Publisher's note Springer Nature remains neutral with regard to jurisdictional claims in published maps and institutional affiliations. 